九州大学学術情報リポジトリ

Kyushu University Institutional Repository

\title{
The Involvement of Nanoscale Zero Valent Iron during the Anaerobic Digestion of Sludge
}

Mokete, Relebohile

Department of Earth System Science and Technology (ESST), Interdisciplinary Graduate School of Engineering Sciences, Kyushu University

Eljamal, Osama

Department of Earth System Science and Technology, Interdisciplinary Graduate School of

Engineering Sciences, Kyushu University

https://doi.org/10.5109/4102486

出版情報: Proceedings of International Exchange and Innovation Conference on Engineering \& Sciences (IEICES). 6, pp. 186-191, 2020-10-22. Interdisciplinary Graduate School of Engineering Sciences, Kyushu University

バージョン：

権利関係 : 


\title{
The Involvement of Nanoscale Zero Valent Iron during the Anaerobic Digestion of Sludge
}

\author{
Relebohile Mokete, Osama Eljamal*, \\ Department of Earth System Science and Technology (ESST), Interdisciplinary Graduate School of Engineering \\ Sciences, Kyushu University, 6-1 Kasuga - Koen Kasuga, Fukuoka 816-8580, Japan \\ Corresponding author email: osama-eljamal@kyudai.jp
}

\begin{abstract}
Increased production of Waste Activated Sludge (WAS) calls for its proper treatment and this can be achieved by biogas production. The aim of this research was to investigate the impact of $1.5 \mathrm{~g} / \mathrm{L}$ NZVI on the generation of bio-methane through the Anaerobic Digestion (AD) process. The results showed that sludge with NZVI (Sg/NZVI) improved the biogas production due to its electron transfer capability. The pH decreased overtime due to the production of Volatile Fatty Acids (VFA) during the AD process, however, the pH of the control decreased more than that of Sg/NVZI because the $H^{+}$was consumed during iron corrosion thus resulting in a favorable pH for the methanogens. But with time, the accumulation of VFA and ammonia resulted in the decreased production of biogas.
\end{abstract}

Keywords: Anaerobic digestion; Sludge; Nano Scale Zero-Valent Iron; Biogas; Methane.

\section{INTRODUCTION}

The currently increasing concern is the expansion of the agricultural and industrial production which results in generation of Waste Activated Sludge (WAS) [1]. The main challenge, therefore, is the treatment and disposal of the WAS [1]. The economically and environmentally friendly way of handling WAS is by generating biogas, particularly methane gas and using the residue as a fertilizer for crops [1]. The main process involved in the production of biogas is called Anaerobic Digestion (AD) which simply involves the degradation of organic matter by microorganisms [2,3]. On its own, AD process is said to be of low efficiency, longer reaction time and it has more limiting steps [4]. Because the AD process on its own is a naturally low process, some additives have been used to stimulate the microorganisms thus enhancing the AD process $[3,4]$. NZVI has been one of the chemical additives that have been successfully applied to enhance the methane gas production because of its high reactivity and its ability to serve as an electron donor [3,5]. Other NZVI advantages include cost effectiveness and environmental friendliness [6, 7]. Metallic iron has the ability to act as an electron donor during its interactions with other species however, its effectiveness is affected by the conditions within which it is introduced [5]. The core of NZVI is known to provide a reducing power for rand it is covered by a shell of iron oxides and hydroxides which are responsible for offering sites for adsorptions and chemical complex formation [6]. Also, the NZVI materials are said to be suitable for various application although there are some limitations encountered in some instances [8]. Such applications include phosphorus removal where about $73.84 \%$ was removed by NZVI within the continuous system [9]. Other materials such as sawdust have been employed as sources of organic carbon to the sulfate reducing bacteria during removal of sulfate from water [10]. The carbon nature within the sawdust is said to be porous thus it enhances the bioremediation processes [11]. Specifically, in AD, NZVI is said to generate ferrous irons and they could also act as extracellular electron donors for some microorganism that participate in the process of $\mathrm{AD}$ [12]. Based on the various metabolic activities, there are four main stages involved in the AD process namely hydrolysis, acidogenesis, acetogenisis and methanogenisis [12]. Because the first stage is considered as the main rate limiting stage of $\mathrm{AD}$, different approaches have been investigated in order to improve the efficiency of hydrolysis and the addition of the nanoparticles such as iron has been considered to be one of the effective techniques because they accelerate the production of methane gas and they produce a stabilized sludge $[2,12]$. The aim of this research is to investigate the influence of a specific dose of $1.5 \mathrm{~g} / \mathrm{L}$ NZVI on the generation of bio-methane from the Thickened WasteActivated Sludge (TWAS) through the AD process.

\section{EXPERIMENTAL}

\subsection{Materials}

Sodium borohydride (> 98.0\%, Sigma-Aldrich Inc., USA) and ferric chloride (>99.0\%, Junsei Chemical Co., Japan) were used to synthesize NZVI nanoparticles. pH adjustment materials include $5 \mathrm{M}$ sodium hydroxide (> 93\%, Wako Co., Japan) and 0.1M hydrochloric acid (35$37 \%$, Wako Co., Japan). Nitrogen $\left(\mathrm{N}_{2}\right)$ gas was used for bubbling. TWAS used as a substrate.

\subsection{Characterization}

\subsubsection{Sampling area and wastewater treatment flow} chart

The TWAS obtained from the Mikasagawa Purification Center (MPC), Fukuoka, Japan. The planned total area of the MPC treatment districts is 9701 hectares (six districts) with the planned total population 676100 . The planned business years of the purification is from the fiscal year of 1971 to 2035 and the sewage removal system is the separate system. The area of the plant site is 18.1 hectares whereas the treatment process of the plant is anaerobic-oxic process plus the rapid filtration thus the treatment capacity of the plant is $267400 \mathrm{~m}^{3} / \mathrm{day}$. 
The treated water is then discharged to Mikasa river (Tokobashi) with the environmental standard of Biological Oxygen Demand of 8ppm or below. The flow chart of the water begins from the influx which simply implies the sewage collection from the various sources then the next stage is the Primary Sedimentation Tank (PST) which is followed by the Biological Reaction Tank (BRT) that is divided into anaerobic, anoxic and oxic chambers. In the anaerobic chamber, organic matter is consumed by the bacteria then converted to phosphate whereas the nitrifying bacteria convert ammonia to nitrate. In the anoxic chamber, nitrate is converted to nitrogen and oxygen. The oxygen provided in the anoxic chamber is then utilized in the oxic chamber where it reacts with phosphate thus removing it. The water then goes to the to the Final Sedimentation Tank (FST) after which it goes to the Disinfection Tank (DT) then it becomes the effluent which is mainly distributed to homes as pure clean water. From the FST, the excess sludge that settles down is passed on to the Belt Type Filtration Concentrator (BTFC) where it is concentrated and part of it joins the sludge from the Gravity Thickener (GT) which is recharged with the sludge settling from the PST. The combined sludge from the BTFC and GT goes to the Digestion Tank (DT) for biogas production which is stored in the Gas Holder $(\mathrm{GH})$. Some of the concentrated sludge from the BTFC goes to the Screw Press Dehydrator (SPD) or Centrifugal Dehydrator (CD) then the combined sludge from these stages goes to either the Melting Furnace (MF) or the Sludge Dryer (SD). In the present case, the sampling point of the sludge was after the BTFC and this sludge is concentrated and very rich in the organic matter hence why it is called the TWAS. The flow chart that indicates the sampling point of the sludge is represented in Fig. 1. Generally, the sludge used in this study was sampled from between point 8 and 4, this implies that it was sampled between BTFC and GT thus the sample is directly from the BTFC (Fig. 1).

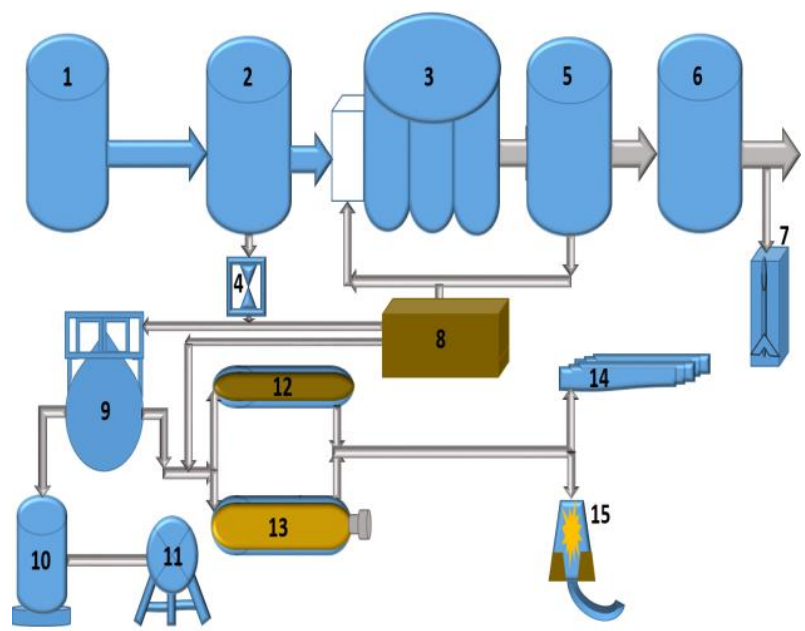

Fig. 1. Flow chart of wastewater treatment process at MPC. The Influx is denoted by 1 whereas $2,3,4,5,6,7$, $8,9,10,11$ or $12,13,14$ and 15 represent Primary Sedimentation Tank (PST), Biological Reaction Tank (BRT), Gravity Thickener (GT), Final Sedimentation Tank (FST), Disinfection Tank (DT), Sand Filtration Equipment (SFE), Belt Type Filtration Concentrator (BTFC), Digestion Tank (DT), Gas Holder (GH), Centrifugal Dehydrator (CD), Screw Press Dehydrator (SPD), Sludge Dryer (SD) and Melting Furnace (MF) respectively.

\subsubsection{Substrate preparation}

The obtained sample was stored in the refrigerator at $5^{\circ} \mathrm{C}$ until it was used. In order to ensure homogeneity, the sludge was stirred for about 10 minutes at 1000RPM before the experiments were conducted. The Total Solids (TS) and Volatile Solids (VS) in the sludge were measured using the standard method. Briefly, the empty petri dish was weighed then $20 \mathrm{ml}$ of sludge was added and the weight of the dish filled with the sludge was recorded. The dish filled with sludge was then placed for one day in the oven whose temperature was maintained at $104^{\circ} \mathrm{C}$. After one day, the dish was taken out of the oven then put in a furnace at $550^{\circ} \mathrm{C}$. The $\mathrm{TS}$ were obtained by subtracting the weight of the dish only (Fig. 2.a) from that of the dish that was put in the oven for 24 hours (Fig. 2.c) whereas the VS were obtained by subtracting the weight of the dish put in the furnace (Fig. 2.d) from that of the dish put in an oven for 24 hours (Fig. 2.c). During the TS and VS measurement, the triplicates were replicated.

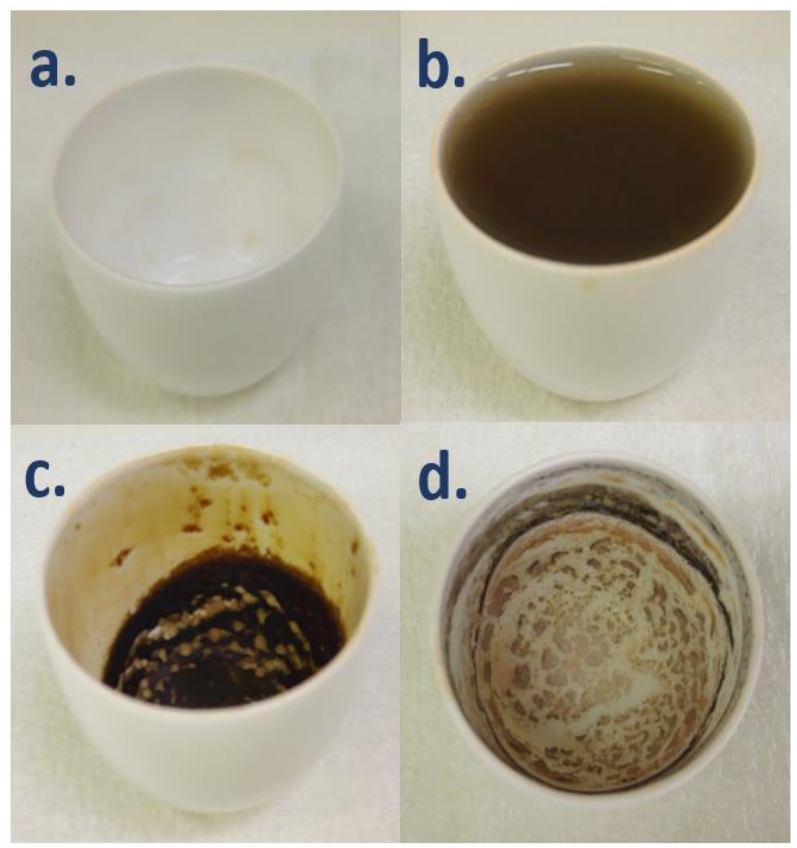

Fig. 2. Total and volatile solids measurement diagram where a. is dish only whereas b. is dish and sludge. C. is the dish put in an oven for 24 hours while $d$. is the sludge filled dish after being put in the furnace for 30 minutes.

\subsection{Batch reactor and set-up}

The batch experiments were conducted in a $200 \mathrm{ml}$ glass bottles and the working volume of TWAS was $150 \mathrm{ml}$. Before the batch experiments, $\mathrm{pH}$ was adjusted to about 7 then $150 \mathrm{ml}$ volume of TWAS was measured and placed in its specific bottle. Two experiments were conducted where one was a control without any additive whereas the dosage of $1.5 \mathrm{~g} / \mathrm{LNZVI}$ was added into the other bottle. The bottles were then sealed with plastic rubbers and the metal caps to ensure that the system was entirely airtight then placed in an incubator whose temperature was $38^{\circ} \mathrm{C}$. The experiments were oxic and no gas was supplied throughout the conduction of the experiments and the system was physically shaken to promote uniformity. The batch experiments were done in duplicates. 


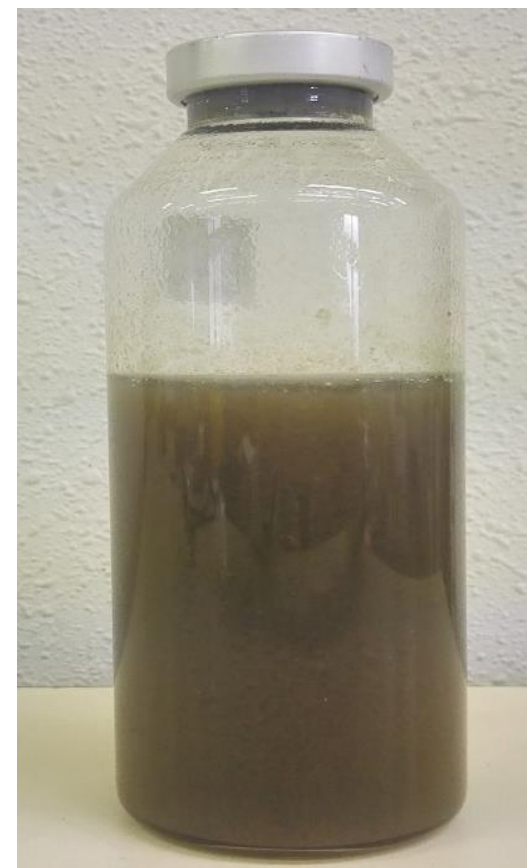

Fig. 3. Schematic diagram for the batch experiment reactor

Fig. 3. represents the schematic diagram of the experimental setup for the batch experiments whereas Table 1 summarizes the initial conditions of the batch experiments.

Table 1. Initial conditions of the batch experiments

\begin{tabular}{ll} 
Parameter & Value \\
\hline Volume $(\mathrm{ml})$ & 150 \\
$\mathrm{pH}$ & $7 \pm 2$ \\
Temperature $\left({ }^{\circ} \mathrm{C}\right)$ & 38 \\
Oxygen & Oxic \\
Shaking & Physical \\
NZVI dose $(\mathrm{g} / \mathrm{L})$ & 1.5 \\
\hline \hline
\end{tabular}

\subsection{NZVI synthesis}

In order to synthesize NZVI, the method namely chemical reduction of ferric chloride with sodium borohydride was used [13]. Equation 1 represents the involved reaction during the synthesis of the NZVI nanoparticles $[13,7]$

$2 \mathrm{FeCl}_{3} \cdot 6 \mathrm{H}_{2} \mathrm{O}+6 \mathrm{NaBH}_{4}+6 \mathrm{H}_{2} \mathrm{O} \rightarrow 2 \mathrm{Fe}^{0}+21 \mathrm{H}_{2}+$
$6 \mathrm{~B}(\mathrm{OH})_{3}+6 \mathrm{NaCl}$

Briefly, Deoxygenated and Deionized Water (DDW) was prepared by purging the nitrogen gas in order to eliminate the oxygen and ensure the deoxygenated conditions. The nitrogen bubbling was in a pattern of $200 \mathrm{ml}, 100 \mathrm{ml}$ and $250 \mathrm{ml}$. In the $200 \mathrm{ml}, 5 \mathrm{~g}$ ferric chloride was added whereas $2.1 \mathrm{~g}$ sodium borohydride was added in the $100 \mathrm{ml}$ DDW. The mixture of ferric chloride was then added to three neck round-bottom flask then the sodium borohydride solution was added dropwise at a pump speed of 10RPM. The reaction was given the ageing time of 5 minutes under the vigorous overhead stirring and continuous nitrogen purging. Fig. 4. below represents the diagram for the NZVI synthesis.

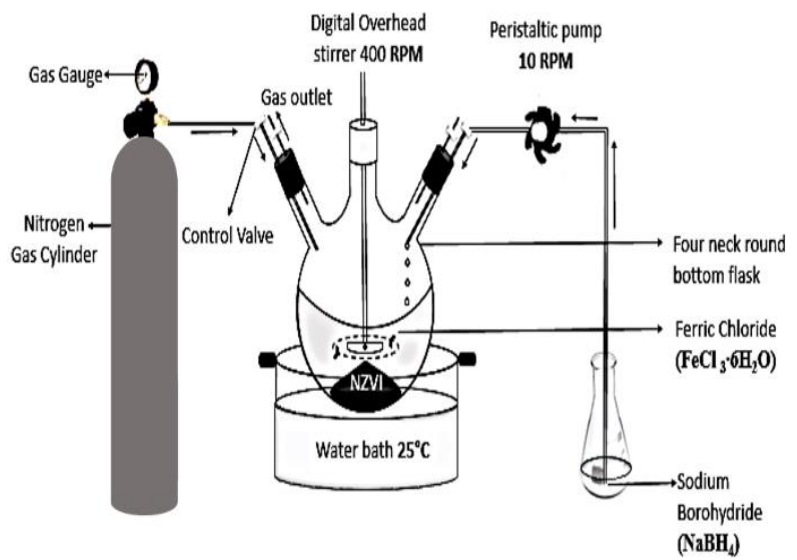

Fig. 4. NZVI synthesis experimental setup

After the completion of the reaction, the NZVI nanoparticles were filtered out using a vacuum filter then washed with the previously prepared $250 \mathrm{ml}$ DDW under $\mathrm{N}_{2}$ purging. The prepared NZVI was then kept and stored in oxygen-free environment until it was used.

\subsection{Analysis}

Freshly synthesized NZVI $[6,7,13,14]$ with a dose of $1.5 \mathrm{~g} / \mathrm{L}$ was added to $150 \mathrm{ml}$ sludge volume (this mixture is referred to as $\mathrm{Sg} / \mathrm{NZVI}$ ) and its reactivity was compared to that of the control $(\mathrm{Sg})$ which had no additive. The volume of the gas was measured using the gas displacement method and the methane gas content was analyzed using a Gas Chromatograph whereas $\mathrm{pH}$ was measured using the $\mathrm{pH}$ meter. The overall experiment time was 42 days and the gas was measured in the pattern of $1,2,3,4,7,10,15,20,25,31,36$ and 42 days.

\section{RESULTS AND DISCUSSIONS \\ 3.1 Characterization}

The $\mathrm{pH}$ of the TWAS was precisely maintained at 6.9 whereas the TS and the VS of the TWAS were found to be $41.4 \mathrm{~g} / \mathrm{L}$ and $33.8 \mathrm{~g} / \mathrm{L}$ respectively as indicated in Table 2. From Table 2, it can be noted that the TWAS was rich in organic matter since the TS value exceeds that of the VS. These results therefore verify the TWAS was a good substrate for biodegradation during $\mathrm{AD}$ in order to generate biogas.

Table 2. Substrate characterization

\begin{tabular}{ll}
\hline \hline Parameter & Value \\
\hline Total solid (g/L) & 41.4 \\
Volatile solids (g/L) & 33.8 \\
$\mathrm{pH}$ & 6.9 \\
\hline \hline
\end{tabular}

\subsection{Biogas and methane production}

The results of cumulative and non-cumulative biogas are shown in Fig. 5.a and b whereas those of cumulative 
methane gas production have been displayed in Fig. 6 . Also, the corresponding $\mathrm{pH}$ results during both the biogas and the methane generation are indicated in Fig. 7.
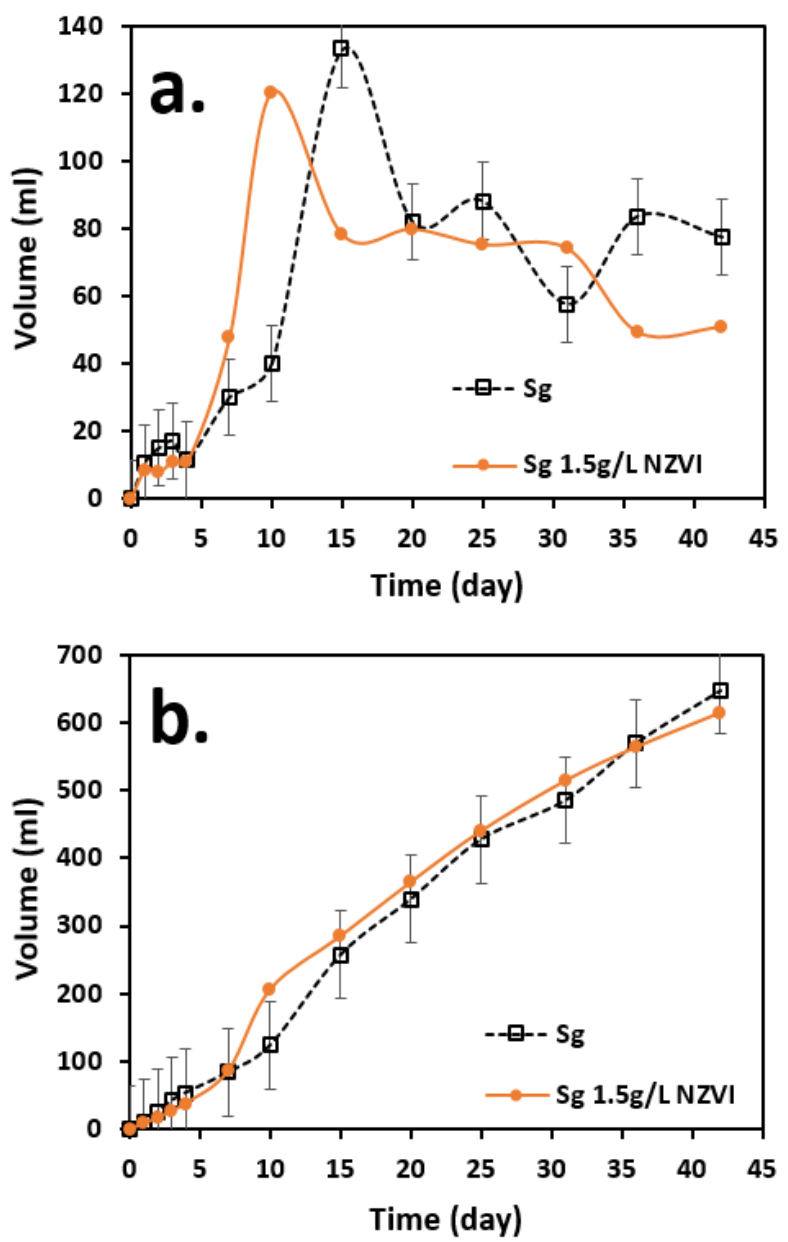

Fig. 5. Profiles of (a) non-cumulative and (b) cumulative biogas production.

As seen on Fig. 5.a, the biogas generation increased from day 1 in both the control and the Sg/NZVI until the respective maximum points were reached at day 10 and 15. After day 10 and 15 , there was a decrease in the biogas production in both the control and the Sg/NZVI until a constant point was reached at day 20 for both batches. It is notable that in the first 4 days, the control produced more biogas than the Sg/NZVI but after day 4, the highest biogas production was attained in the presence of NZVI whereby a peak value of $120.5 \mathrm{ml}$ was attained at day 10 as opposed to the control whose peak value was $133.2 \mathrm{ml}$ at day 15 . This could be due to the rapid corrosion of NZVI in its fresh form thus enhancing the $\mathrm{AD}$ hence the biogas generation $[7,15]$. Also, the AD process is considered to be a naturally slow process with longer reaction time and low efficiency hence why the presence of NZVI stimulated the biogas production earlier than the control [3,4]. The highest biogas production achieved by the control at day 15 could be due to the fact that in the presence of NZVI, rapid oxidation led to rapid production of the Volatile Fatty Acids (VFAs) which could have affected the reaction system negatively $[13,16,14]$. This also explains why at day 42 the control had the higher value of biogas $(77.6 \mathrm{ml})$ than the control $(50.9 \mathrm{ml})$ as presented on Fig. 5.a. With respect to the non-cumulative biogas yield results, the biogas production increased steadily from day 0 up to day 42 . Initially, the control showed a slightly higher biogas production which was surpassed by that of the Sg/NZVI mixture at day 7 . During day 42, the control produced more biogas $(647.1 \mathrm{ml})$ than the $\mathrm{Sg} / \mathrm{NZVI}$ whose maximum value was $614.1 \mathrm{ml}$ (Fig. 5.b). Accordingly, the trend of the produced methane gas was almost similar although the methane gas production was nearly the same during the first 4 days (Fig. 6). Ultimately, the control produced the highest methane gas content particularly at day 42 thus reaching the maximum of $648.86 \mathrm{ml}$ as opposed to the Sg/NZVI whose value was $558.04 \mathrm{ml}$ (Fig. $6)$.

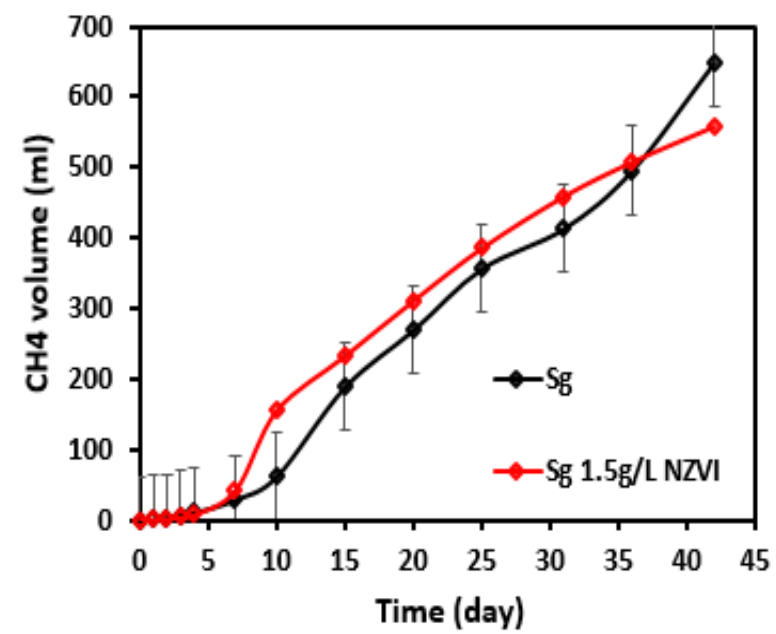

Fig. 6. Profile of cumulative methane gas production.

The production of Volatile Fatty Acids (VFA) at the acidogenesis stage of $\mathrm{AD}$ led to the decreasing $\mathrm{pH}$ values in Fig. 7 [15]. Besides, the pH curve (Fig. 7) explains the observed trends in both Fig. 5.b and 6. As seen on Fig. 7, the $\mathrm{pH}$ decreased in both the control and Sg/NZVI to a certain level but the control had the least $\mathrm{pH}$ than that of the $\mathrm{Sg} / \mathrm{NZVI}$ and this is due to the consumption of $\mathrm{H}^{+}$ during iron corrosion thus maintaining a favorable $\mathrm{pH}$ for the methanogens which generally increased the biogas and methane gas yield (Fig.5.b and 6) [17].

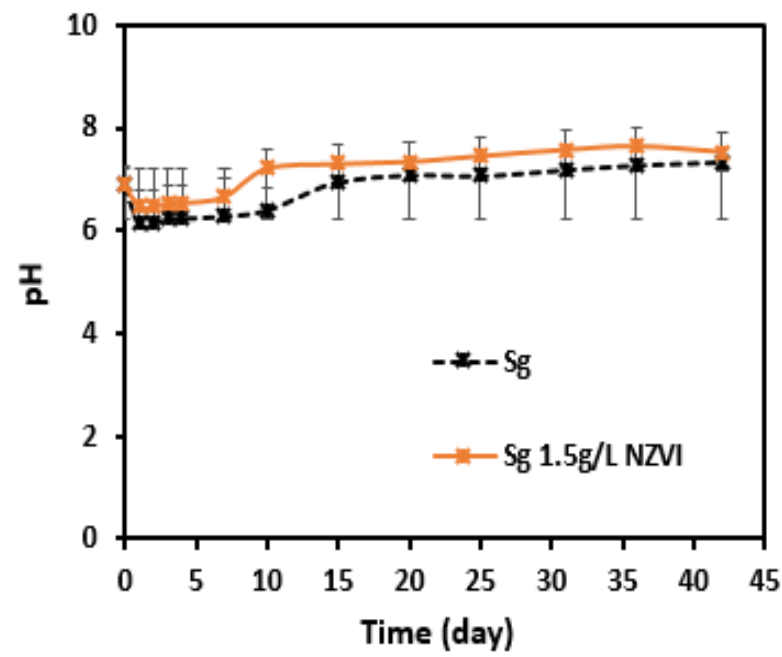

Fig. 7. Corresponding $\mathrm{pH}$ profile during biogas and methane gas production. 
Accordingly, the iron serves as an electron donor to increase the hydrolysis and fermentation during the AD process and the evolution of hydrogen during iron corrosion might have been responsible for promoting hydrogenotrophic methanogenesis as well as homoacetogenesis [18, 19]. Because AD process is enhanced in the presence of iron, the decrease of the biogas and methane yield after day 36 in Sg/NZVI (Fig. 5.b and 6) can be due to the increased production of VFA and ammonia generated during the bioconversion of nitrogenous compounds such as proteins thus resulting in both VFA and ammonia accumulation which in turn inhibit the methanogens activity [16].

\section{CONCLUSIONS}

TWAS is very rich in organic matter hence it leads to the increased production of biogas. Furthermore, NZVI improves the production of biogas because it serves as an electron donor and it results in the consumption of $\mathrm{H}^{+}$ which in turn creates a favorable $\mathrm{pH}$ for the methanogens to produce methane gas. During the AD process, $\mathrm{pH}$ decreases due to the production of the VFA. Also, ammonia gas is produced during the AD process and its high concentration along with that of VFA can result in the inhibition of the AD process hence decreased gas production.

\section{REFERENCES}

[1] X. Yang, J. Nie, D. Wang, Z. Zhao, M. Kobayashi, Y. Adachi, K. Shimizu, Z. Lei, Z. Zhang. Enhanced hydrolysis of waste activated sludge for methane production via anaerobic digestion under N2nanobubble water addition. Science of the Total Environment 693 (2019) 133524.

[2] F. Suanon, Q. Sun, D. Mama, J. Li, B. Dimon, C. Yu, Effect of nanoscale zero-valent iron and magnetite (Fe3O4) on the fate of metals during anaerobic digestion of sludge. Water Research 88 (2016) 897-903.

[3] E. Abdelsalam, M. Samer, Y.A. Attia, M.A. AbdelHadi, H.E. Hassan, Y. Badr. Influence of zero valent iron nanoparticles and magnetic iron oxide nanoparticles on biogas and methane production from anaerobic digestion of manure. Energy 120 (2017) 842-853

[4] J. Zhou, X. You, T. Jia, B. Niu, L. Gong, X. Yang, Y. Zhou. Effect of nanoscale zero-valent iron three phase change in sludge anaerobic digestion. Environmental Technology 41 (2020) 3199-3209.

[5] R.A. Crane, T.B. Scott. Nanoscale zero-valent iron: Future prospects for an emerging water treatment technology. Journal of Hazardous Materials 211212 (2012) 112- 125.

[6] R. Mokete, H. Yifan, O. Eljamal, N. Matsunaga. Investigation on Nanoscale Zero Valent Iron interactions in aqueous solution. Proceedings of International Exchange and Innovation Conference on Engineering \& Sciences (IEICES) 3 (2017) 149152.
[7] R. Mokete, K. Chen, O. Eljamal, N. Matsunaga. Inspection of Iron-Copper Bimetal Performance in Chemically Altered Atmosphere. Proceedings of International Exchange and Innovation Conference on Engineering \& Sciences (IEICES). 4 (2018) 6669.

[8] A. M.E. Khalil, O. Eljamal, B. B. Saha, N. Matsunaga. Performance of nanoscale zero-valent iron in nitrate reduction fromwater using a laboratory-scale continuous-flow system. Chemosphere 197 (2018) 502-512.

[9] S. Takami, O. eljamal, A. M. E.. Khalil, R. Eljamal, N. Matsunaga. Development of continuous system based on nanoscale zero valent iron particles for phosphorus removal. Journal of JSCE 7 (2019) 30-42.

[10] O. Eljamal, K. Jinno, T. Hosokawa. Modelling of solute transport and biological sulfate reduction using low cost electron donor. Environmental Geology 56 (2009) 1605-1613.

[11] O. Eljamal, K. Jinno, T. Hosokawa. Modelling of solute transport with bioremediation processes using sawdust as a matrix. Water, Air and soil Pollution 195 (2008) 115-127.

[12] Y. Xiang, Z. Yang, Y. Zhang, R. Xu, Y. Zheng, Ji $\mathrm{Hu}, \mathrm{X}$. Li, M. Jia, W. Xiong, J. Cao. Influence of nanoscale zero-valent iron and magnetite nanoparticles on anaerobic digestion performance and macrolide, aminoglycoside, $\beta$-lactam resistance genes reduction. Bioresource Technology 294 (2019) 122139.

[13] R. Mokete, O. Eljamal, Y. Sugihara. Exploration of the reactivity of nanoscale zero-valent iron (NZVI) associated nanoparticles in diverse experimental conditions. Chemical Engineering and Processing - Process Intensification 150 (2020) 107879.

[14] O. Eljamal, R. Mokete, N. Matsunaga, Y. Sugihara. Chemical pathways of Nanoscale Zero-Valent Iron (NZVI) during its transformation in aqueous solutions. Journal of Environmental Chemical Engineering 6 (2018) 6207-6220.

[15] C.M. Ajay, S. Mohan, P. Dinesha, M. A. Rosen. Review of impact of nanoparticle additives on anaerobic digestion and methane generation. Fuel 277 (2020) 118234.

[16] Q. Yin, M. Gu, G. Wu. Inhibition mitigation of methanogenesis processes by conductive materials: A critical review. Bioresource Technology 317 (2020) 123977.

[17] J. Wei, X. Hao, M. C.M. van Loosdrecht, J. Li. Feasibility analysis of anaerobic digestion of excess sludge enhanced by iron: A review. Renewable and Sustainable Energy Reviews 89 (2018) 16-26. 
[18] X. Hao, J. Wei, M. C.M. van Loosdrecht, Daqi Cao. Analysing the mechanisms of sludge digestion enhanced by iron. Water Research 117 (2017) 58-67.

[19] T. Jia, Z. Wang, H. Shan, Y. Liu, L. Gong. Effect of nanoscale zero-valent iron on sludge anaerobic digestion. Resources, Conservation \& Recycling 127 (2017) 190-195. 